of intra-cranial hamorrhage, usually meningeal, or of atrophy of the brain from whatever cause.

To return to the special case under consideration. 'To what in this case is the spastic condition due? Is it an exception to the general rule, and may a spina bifida so act upon the lateral columns by pressure or otherwise as to produce a spastic paraplegia, or is it due to some other cause?

In regard to the possibility that a spina bifida should cause a permanent spastic contracture in the lower extremities, I should not wish to express an absolute opinion, but in any case it is very rare. It is true that paralyses of the lower extremities are not uncommon in spina bifida, occurring according to the statistics of the Committee of the Clinical Society of London in about one-fifth of the cases - 53 out of $244-$ and this percentage is probably much too small. But these paralyses are not spastic in character, and do not lead to spastic contractures.

(Certain cases have been reported in new-born children where with spina bifida the lower extremities were held in a position of flexion, the thighs flexed on the abdomen, and the legs on the thighs; but in these there does not appear to have been any true spastic contracture. Dollinger reports a case of temporary spastic contraction of the muscles of the lower extremities, which disappeared when the sac was emptied, and reappeared as it refilled. The sac was in the lumbar region.)

I have thus far been unable to find any account of spastic contractures occurring in uncomplicated spina bifida. In our case, moreover, several special reasons combine to render the hypothesis of its direct origin from the spina bitida improbable. In the first place, the paraplegia is of what we may call the pure type - that is, uncomplicated by symptoms referable to other portions of the cord than the lateral columns. This in children is practicully al ways cerebral (primary lateral sclerosis in them being almost unknown); secondly, it is difficult to understand how a spina bifida in the lumbar region could cause an affection of both lateral columns of the cord without more evidence of the affection of other portions.

But if the spina bifida is not the cause of these contractures, to what then are they due? In this and in all similar cases I believe these spastic paraplegix to be cerebral, and to be the result of the accompanying hydrocephalus. Spastic contractures in connection with secondary hydrocephalus are very common, but may, perhaps, more fairly be considered in many cases as the result of the primary lesion. In hydrocephalus, however, which appears idiopathic and primary, they are less common, but more frequent than is sometimes supposed.

Hydrocephalus connected only with spina bifida, as in our case, and not due to cerebral disease, must be considered primary. In connection with the late development of the contractures in our case that of Anton may be mentioned, where, in a case of congenital hydrocephalus, spastic contractions appeared in the previously unaffected extremities at the age of nine. This late appearance in primary hydrocephalus is probably not uvcommon.

In this case, and in similar ones, therefore, I am inclined to believe that the spastic paraplegia is not directly due to any effect on the cord occasioned by the spina bifida, but is the indirect result of the accompanying hydrocephalus. The exact steps by which this result is produced are not yet wholly proved, but the numerous investigations now going on, on this and analogous subjects, render it not improbable that we may before long obtain a more exact knowledge of them.

\section{Uliniral gDepartment.}

\section{A CASE OF THE PHELPS OPERATION FOR} TALIPES EQUINO-VARUS: RESUL'TS.'

HY II. W. CUBHINo, M.D.

Assistant Suryeon to the Children's Ilospital.

Tue accompanying illustrations represent some casts of the foot of an otherwise well-developed patient, age eight years, which I thought might be of interest in connection with the "Phelps" operation. The first (Fig. 1) shows a congenital talipes equinovarus of the more severe type. A foot which was unyielding to any attempt at manual redressement. The patient walked, as the callus shows, almost on the dorsum of the foot. 'The toes point inward ninety degrees from the normal position, and are elevated. You can thus appreciate the amount of bony distortion and contraction of soft parts which must have attended such a deformity.

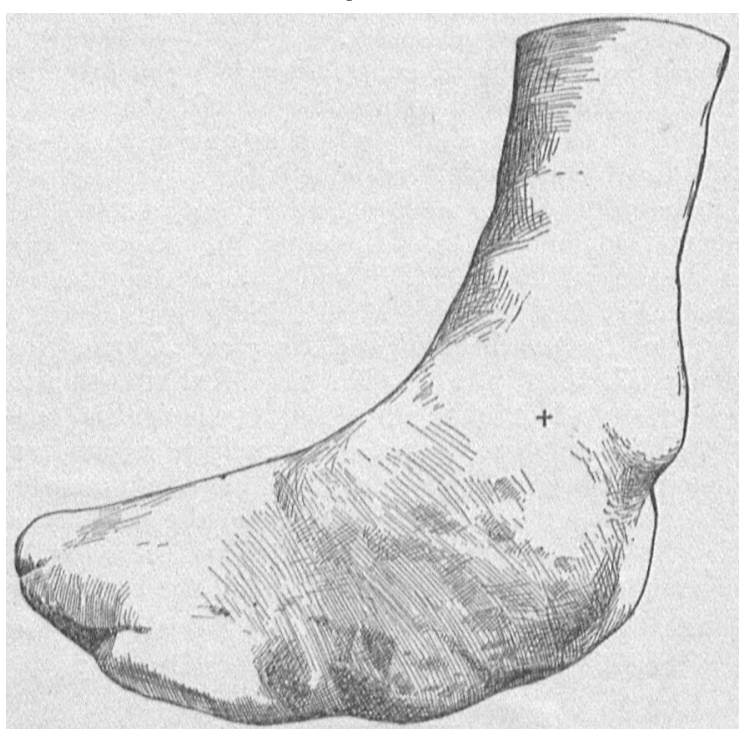

Fsa. 1. The $x$ is at a point on the anterior gurfuce of the ankle joint, midway betweon tho malleoll.

'This foot I treated by the "Phelps" method. An unsuccessful attempt at redressement under ether. Then a tenotomy of the tendo Achilles and plantar fascia. Then through the vertical incision, which Phillipson has so well described, a division successively of the tibialis posticus, abductor pollicis, flexor longus digito. rum, flexor longus pollicis, deltoid ligament, the inner half of the flexor brevis digitorum and flexor accessorius.

After division of each, an attempt was made to correct the deformity. Sometimes the foot yielded; at others no gain was attained. At length, as I was about to attack the astragalus, a final effort caused something to yield in the mid-tarsus, and the foot came eusily into good position, leaving a wedge-shaped defect one inch wide at its cutaneous surface and ex-

1 Read before the Surgica] Section of the Sulfolk Distriot Mediea Soclety, Fobruary 3,1802 . 
tending from the centre of the sole to the level of the internal malleolus. During these manipulations the internal plantar vessels, which were unusually small and had been dissected free with great difficulty, were ruptured.

The wound healed in the usual manner, by the Schéde method (without complication), and was practically closed at the first dressing, twenty-one days after the operation. The complete organization of the clot and the final removal of all dressing was about the fortieth day.

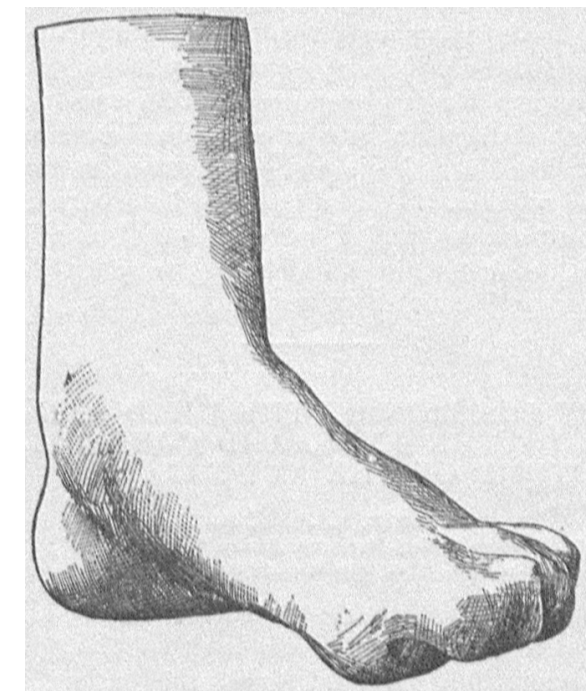

Fia. 2.

Three and one-half months after the operation this cast (Fig. 2) was taken. During this time the patient wore a Taylor club-foot shoe. At this date all apparatus was omitted. The foot is perfectly straight, especially the anterior part so often seen still somewhat inverted after operative treatment. The sole is in its normal position. There is no equinus. 'The patient can flex the ankle beyond a right angle, and walks without a limp.

The points of interest in this case have been :

(1) The completeness of the reduction of the deformity.

(2) 'The small cicatrix, that is, small when the original gaping wound replaced by it is recalled.

(3) The amount of pain immediately following the operation. Quite marked for twenty-four hours. Then gradually diminishing, and finally ceasing at the end of the third day.

(4) The tendency at present of the foot to assume a position of valgus apparently from a lack of support of its inner edge. 'This happens at times in cases treated by torsion and other operative methods, and can be controlled in this case if it shows a tendency to increase. It may disappear as the cicatrix becomes firmer. It is now noticed only when the foot has to support the weight of the body as in standing, walking or similar attitudes.

I contribute this record as a proof of the efficiency of Dr. Phelps's method, and to show the result which may be attained by it.

The Long Island (N. Y.) College Hospita L. The Thirty-third Annual Commencement was hold ou March 23d. The graduating class numbered 64 .

\section{A CASE OF DOUBLE CONGENITAL CIUB-FOOT} IN THE ADUL'T.'

\author{
BY A. THORNDIKE, Mt.D.
}

I HAVE always regarded it as a curious and significant fact that many of the severe and neglected forms of club-foot, those which defy the ordinary and more gradual methods of correction by mechanical appliances, can be cured and serviceuble limbs obtained without any cutting or removing of bone; and I have ventured to present this report of a single case in order to illustrate this fact and see what deductions, if any, could be drawn from it for our guidance in treating club-feet of this so-called resistunt class.

S. C. single, twenty-eight years old, was referred to me last June, by Dr. George Haven, and admitted to the House of the Good Samaritan, June 29th. She was the oldest of five children, who, with the parents, were all, excepting her, free from malformations; maternal impressions were not considered to have influenced her condition, and she was not otherwise deformed. She complained of pain and tenderness in her feet, and said that this was so troublesome that after doing a little housework on one day she usually was obliged to spend the next two on a lounge or in bed.

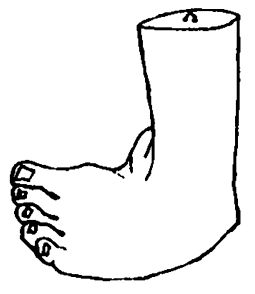

Fia. 1.

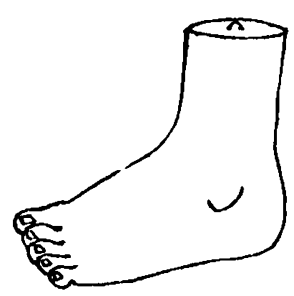

Fia. 2.
She was thin. poorly developed, and very short; she walked with a waddling grait, rolling considerably, and bore her weight on the outer sides of her boots; the toes were turned in, so as to point directly at each other. The feet were kept widely apart in stepping, and she required assistance to keep her balance. 'The deformity was precisely alike on both sides, and is best seen by referring to the cut, Fig. 1, drawn from a plaster cast of the left foot taken at entrance. Figure 2 is from a cast of the same foot made January 10 , 1892. 'The heel was lifted posteriorly, and was twisted in, so that in standing the plantar surface of the heel was turned inward and backward, while the anterior sole was drawn in by the contructed plantar fascia, so that it lay in a plane facing directly backwards. 'The tarsus was very prominent, and the metatarsal bones and toes, instead of lying alongside of each other as in a normal foot, were rotated so as to lie vertically one above the other; the toes also pointed a little upwards as well as inwards. The outer maleolus nearly touched the ground in standing, and its outline was lost in a large tender callous which surrounded it and extended along the outer border of the foot. It was an equinovarus of a severe type. 'The deformity did not yield much to pressure with the hand; but very little force could be used without cansing pain. Under ether, it was evident that her weight was borne chiefly on the auterior surface of the calcaneus and a part of the cuboid.

1 Read before the Surgical Section of the Sutfolk Distriet Medical Soolety, Fobruary 3,1892 . 